\title{
ESCOLA DE FORMAÇÃO DE "PROFESSORAS": AS RELAÇÕES DE GÊNERO NO CURRÍCULO SUPERIOR DE EDUCAÇÃO FÍSICA'
}

\section{MS. VIVIANE TEIXEIRA SILVEIRA}

Mestre em Educação pela Universidade Federal do Paraná (UFPR), Doutoranda no Programa de Pós-Graduação Interdisciplinar em Ciências Humanas (PPGICH) da Universidade Federal de Santa Catarina (UFSC) (Florianópolis - Santa Catarina - Brasil)

E-mail: vividich@gmail.com

\section{DR. LUIZ CARLOS RIGO}

Professor associado da Escola Superior de Educação Física (ESEF) da Universidade Federal de Pelotas (UFPel), Doutor em Educação na Universidade Estadual de Campinas.

(Pelotas - Rio Grande do Sul - Brasil)

E-mail: Icrigo@terra.com.br

\section{DR ${ }^{a}$. MARIA RITA DE ASSIS CÉSAR}

Professora adjunta no Setor de Educação da Universidade Federal do Paraná (UFPR),

Doutora em Educação na Universidade Estadual de Campinas (UNICAMP)

(Curitiba - Paraná - Brasil)

E-mail: mritacesar@yahoo.com.br

\section{DR ${ }^{\mathrm{a}}$. ELIANE RIBEIRO PARDO}

Professora associada da Escola Superior de Educação Física (ESEF) da Universidade Federal de Pelotas (UFPel), Doutora em Educação na Universidade Federal do Rio Grande do Sul.

(Pelotas - Rio Grande do Sul - Brasil)

E-mail: elipardo@terra.com.br

\section{RESUMO}

As relações de gênero continuam sendo um tema recorrente no campo da Educação Física. Nesse sentido, este artigo teve como objetivo investigar como as relações de gênero estiveram presentes na emergência e na consolidação do currículo da Escola Superior de Educação Física da Universidade Federal de Pelotas (ESEF/UFPel). A metodologia utilizada para realizar a pesquisa foi a História Oral. Assim, através da coleta de cinco (5) depoimentos orais, de fontes históricas escritas (jornais, atas e documentos avulsos) e de um suporte teórico pósestruturalista, concluímos que a emergência da ESEF/UFPel e as suas práticas curriculares nos anos de 1970 e 1980 estiveram atreladas a discursos e a práticas que reiteraram a maximização das diferenças entre os sexos, entre homens e mulheres.

PALAVRAS-CHAVE: Currículo; relações de gênero; memória institucional; formação de professoras.

I. Este artigo é oriundo de uma dissertação de mestrado que contou com o apoio financeiro da CAPES (modalidade bolsa de mestrado) e da Rede Cedes, Ministério do Esporte. 
Este artigo é resultado de uma pesquisa que teve como objetivo principal fazer uma análise sobre as relações de gênero presentes nos discursos e nas práticas curriculares que atuaram na formação das professoras de Educação Física da ESEF/ UFPel, nas décadas de 1970 e 1980².

Entre os motivos que justificam esse recorte temporal, destacam-se: a fundação da Escola Superior de Educação Física (ESEF/UFPel), em I 971 , a presença de um número elevado de mulheres, principalmente nas primeiras turmas da ESEF/NFPel ${ }^{3}$, e o contexto pelo qual passava a Educação Física brasileira nesse período, marcado por um movimento de proliferação de novos cursos superiores de Educação Física por todo o território nacional ${ }^{4}$.

Em termos teóricos, a pesquisa abordou a problemática do gênero, tratada a partir dos Estudos Feministas de Butler, (1998, 200 I, 2003); Louro, (1997a, 1997b, 200 I); Héritier-Augé, ( 1996); Kehl, (1996); o currículo, analisado a partir das contribuições de Thomaz Tadeu da Silva (1999, 2000, 2003). Além disso, o estudo também teve como referência as contribuições de Michel Foucault, principalmente para tratar da sexualidade/subjetividade (1979, 1984a, 1984b) e das relações de poder (1977, 1979, 1987). Mas, mais do que aplicar os conceitos desses autores, os utilizamos como uma "caixa de ferramenta", procurando pensar com eles, pois,

2. Especificamente sobre a história e as memórias de outras instituições de formação de professores de curso superiores de Educação Física algumas contribuições podem ser encontradas nos artigos: MAZO, 1997, 2005; GOELLNER et al., 2005.

3. Essa presença feminina pode ser ilustrada pelo número de mulheres formandas na turma de 1976; de um total de 31, 24 eram mulheres: Cleonice Hax, Cleusa Rodrigues, Elen Barros, Elisabeth Silva, Gilce Bezerra, Irma Silva, Cátia Louzada, Lilian Duarte, Loude Montezano, Maria da Silva, Maria Hipólito, Maria de Azevedo, Maria Bueno, Melania Bechia, Miriam Tavares, Neusa de Brito, Regina Quintana, Regina Bohm, Regina Koabere, Ruth Crochemore, Saleti Rodrigues, Sandra da Silva, Tânia Medeiros e Vera Rapeto fizeram parte dessa turma. Dados retirados do Acervo ESEF/UFPel, 2005.

4. Sobre a proliferação dos cursos superiores de Educação Física no início dos anos de 1970 podemos tomar como exemplo o caso do Rio Grande do Sul, onde, entre 1970 e 1973, além da Escola Superior de Educação Física da Universidade Federal de Pelotas, foram criados outros oito (8) novos cursos: Escola Superior da Fundação Educacional do Vale do Jacuí (1970), em Cachoeira do Sul; Escola Superior de Educação Física de Santa Cruz do Sul ( 1970$)$; Instituto Porto Alegre-IPA ( 197 I); Fundação Universitária de Passo Fundo ( 197 I); Faculdade de Educação Física da Associação de Professores de Cruz Alta - APROCRUZ (1973); Faculdade de Educação Física da Fundação Átila Taborda - FURBA (1 973), em Bagé; Escola de Educação Física da FEEVALE ( 1973), em Novo Hamburgo; Centro de Educação Física e Desporto ( 1970), em Santa Maria, (MAZO, 1997). Assim, em 1973, junto com a pioneira Escola Superior de Educação Física da Universidade Federal do Rio Grande do Sul (ESEF/NFRGS), fundada em 1940, o estado passou a contar com mais nove (9) outros cursos superiores de Educação Física. 
como salienta Michel Foucault, apropriar-se de um autor pressupõe "[...] utilizá-lo, deformá-lo, fazê-lo ranger, gritar" (1979, p. 143)5.

\section{CONSIDERAÇÕES METODOLÓGICAS}

Em um primeiro momento, buscamos fontes escritas junto ao acervo da ESEF/ UFPel. Foram utilizados registros tais como as ementas das disciplinas, os cadernos de informações aos calouros, as atas de reuniões departamentais, as notícias publicadas nos jornais da cidade, referentes à situação da Educação Física na cidade e à criação da Escola Superior de Educação Física. A utilização desses registros serviu de referência para nos mostrar um pouco do discurso institucional, principalmente aquilo que a instituição guarda e quer mostrar, um pouco da sua história registrada.

Após a análise das fontes escritas, coletamos cinco depoimentos orais com ex-alunas e ex-professoras da ESEF ${ }^{6}$, que assinaram um termo de consentimento autorizando a utilização pública de seus depoimentos. As cinco entrevistadas eram brancas e pertenciam à classe média, perfil predominante das mulheres brasileiras que ingressavam na universidade no início dos anos 70. As entrevistas foram realizadas a partir do referencial teórico metodológico oriundo da História Oral. A nossa utilização dessa Metodologia teve como referência as contribuições de autores como Paul Thompson (1992), quando chama a atenção para cuidados éticos entre entrevistador e entrevistado que devem acompanhar a realização de toda entrevista de História Oral; de Alessandro Portelli (20 I0), quando lembra que "os historiadores orais citam muito mais amplamente as palavras de suas fontes" e, sempre que possível, "revelam nome e sobrenome dos narradores, reconhecendo-os como autores de suas histórias" (PORTELLI, 2010, p. 216). Destacamos também as contribuições

5. Outras considerações sobre o uso de autores e o conceito de caixa de ferramenta no pensamento de Michel Foucault, consultar o artigo de Francisco Jódar e Lucía Gómez (2004).

6. As entrevistadas foram: CLARK, I. C., formada na Universidade Federal do Rio Grande do Sul em 1960, trabalhou na ESEF no período de 1974 a 1984, ministrava a disciplina de Voleibol (para as mulheres!). ESTEVES, W. M., nascida em 1924, foi uma das primeiras professoras de Educação Física da cidade de Pelotas e uma das fundadoras da ESEF/UFPel, formada em 1944 no curso Normalístico Especializado em Educação Física na Escola de Educação Física de Porto Alegre. CUNHA, M. E. H., foi aluna da ESEF/UFPel no período de 1976 a 1980, trabalhou a maior parte de sua vida na Escola Técnica Federal de Pelotas (atual Instituto Federal Sul-Rio-Grandense), sempre ministrando aulas para turmas separadas por sexo. FARIAS, T.C., nascida em I93I, foi professora da disciplina de Rítmica na ESEF/UFPel e incentivadora inicial das aulas de Rítmica para os homens. MARTINS, E. F., nascida em 1952, foi a mais jovem das entrevistadas e foi aluna da primeira turma da ESEF/ UFPel, logo após sua formação já foi nomeada professora da disciplina de Ginástica, aposentou-se em 1995 pela mesma instituição. Todas as entrevistas foram realizadas na cidade de Pelotas, Rio Grande do Sul, Brasil durante o ano de 2007. 
teórico-epistemológicas que buscamos em Antonio Montenegro ( 1997$)$, quando ele lembra a importância da História Oral pautar-se por um olhar interdisciplinar e, principalmente, quando ele aponta para uma História Oral na qual "[...] a análise histórica tem como foco primordial as relações, os percursos, as práticas, porque através do seu estudo é que se poderão construir outras formas de compreensão, que desnaturalizam a relação ou a representação que procurava associar de forma unívoca o objeto ou a coisa a palavra" (MONTENEGRO, 20 I0, p. 3 I). Ele acrescenta ainda que "é nessa perspectiva que Deleuze e Veyne reafirmam a proposta de Foucault de rachar as palavras, rachar as coisas; desnaturalizá-las e ir em busca dos fios que as engendram, que as significam" (MONTENEGRO, 20 I0, p. 31).7

A rede de depoentes aliada com as fontes documentais nos propiciou um solo empírico razoável, para construir um corpo de conhecimento da memória feminina da formação docente em Educação Física na ESEF/UFPel, nas décadas de 1970 e 1980. A análise feita procurou abarcar o conjunto das fontes (orais e escritas), respeitando a singularidade e as diferenças de natureza existentes entre elas. Assim, apesar de nem todas as entrevistas terem sido citadas diretamente no artigo, foi a partir delas que aprofundamos certos indícios encontrados nos registros escritos. Se os registros escritos representam a versão que a instituição preserva, as entrevistas representaram outra face da história, um pouco do currículo oculto da instituição pesquisada. Segundo SILVA (2000, p. 33), currículo oculto pode ser definido como um "conjunto de atitudes, valores e comportamentos que não fazem parte explícita do currículo, mas que são implicitamente 'ensinados' através das relações sociais, dos rituais, das práticas e da configuração espacial e temporal da escola". Nesse sentido, as dimensões do gênero e da sexualidade como, por exemplo, como ser homem, como ser mulher, como ser heterossexual, também passa pelo currículo, mesmo não estando explícitas na grade curricular (SILVA, 1999).

\section{A EMERGÊNCIA DE UMA INSTITUIÇÃO DE ENSINO SUPERIOR}

As discussões sobre a implantação da Escola Superior de Educação Física de Pelotas - ESEF iniciaram-se em 1969, por meio do Conselho Municipal de Desportos, influenciado pela criação da lei federal que estendeu a obrigatoriedade da prática da Educação Física a todos os níveis de ensino ${ }^{8}$.

7. Outras considerações teóricas e metodológicas referentes à História Oral podem ser encontradas em: Amado e Ferreira (1998) e Ferreira (2000).

8. O decreto-lei $n^{\circ} 705$ de 25 de junho de 1969 alterou o artigo $22^{\circ}$ da lei $n^{\circ} 4024 / 6$ I, tornando obrigatória a prática da Educação Física a todos os níveis e ramos de ensino. Anos depois, a Educação Física é regulamentada em todos os níveis de ensino pelo Decreto nº 69450 de $I^{\circ}$ de novembro de 
Com a aprovação dessa lei ganharam mais coro as reivindicações que clamavam por um curso superior de Educação Física, pois a região convivia com a falta de professores e professoras com formação superior nessa área. Dos poucos professores/as que trabalhavam com essa disciplina, a maioria possuía registros a título precário?. A professora Waniza conta que:

[...] surgiu à idéia primeiro do Conselho Municipal de Desportos [...] e foi na época que veio o Decreto-Lei, se não me falha a memória, que era obrigatória a Educação Física em todos os níveis de ensino, então a universidade não tinha nada nessa época. Eu era supervisora da antiga DE [Delegacia de Educação] então eu estava muito a parte de todas as necessidades da região. E o [...] Reitor da UFPEL na época expediu o pedido de criar uma Escola de Educação Física, aí eu fui convidada [...] (ESTEVES, 2007).

Em 04/I 0/1969, uma reportagem no Jornal Diário Popular, intitulada "Educação Física para 12.000 alunos, apenas 24 professôres” (ROSA, 1969b, p. 5), assinada por Mário Rosa, trazia uma mostra sobre a situação da Educação Física nos estabelecimentos de nível médio na cidade de Pelotas/RS: de 24 professores, onze possuíam registro a título precário; treze possuíam registro definitivo, mas apenas cinco fizeram curso superior; quatro fizeram o curso de Educação Física Infantil, enquanto os quatro restantes concluíram o curso da especialidade no Exército ${ }^{10}$.

Noutra reportagem, datada de 24/08/1969, do mesmo jornal, intitulada "Conselho Municipal de Desportos pediu criação de escola de Educação Física na UFPEL" o autor da matéria comenta que:

[...] a falta de uma Escola de Educação Física em Pelotas é responsável, em grande parte, por uma série de problemas: I) carência de professôres da disciplina: existem 24 professôres para atender 12.000 alunos do ensino médio; no nível primário, a escassez é ainda maior; 2) grande número de professôres com registro a título precário, obrigados a fazer estágio,

1971, artigo $2^{\circ}$ - "A educação física, desportiva e recreativa integrará, como atividade escolar regular, o currículo dos cursos de todos os graus de qualquer sistema de ensino". E tinha por objetivos citados no artigo $3^{\circ}$, inciso III: "No nível superior, em prosseguimento à iniciada nos graus precedentes, por práticas, com predominância, de natureza desportiva, preferentemente as que conduzam à manutenção e aprimoramento da aptidão física, à conservação da saúde, à integração do estudante no campus universitário à consolidação do sentimento comunitário e de nacionalidade".

9. O professor de Educação Física com registro a título precário tinha de, anualmente, fazer em Porto Alegre um estágio - geralmente de 5 dias - para poder renovar sua autorização para lecionar; o que causava uma situação funcional de insegurança.

10. Nesse período, a maioria dos/as professores/as da disciplina de Educação Física não tinha formação superior. Os que obtinham o registro a título precário eram formados no Magistério e, desses, alguns faziam um curso de Educação Física Infantil, porém ministravam aulas a todos os níveis de ensino. Outros tinham sua formação na área militar, mas a maioria dos/as professores/as não fazia curso superior em Educação Física, o que não os impedia de exercerem tal função. 
anualmente, em Porto Alegre, para renovação do registro e trabalhando num regime de insegurança, pois os novos titulados têm preferência; 3) ensino inadequado da Educação Física para as jovens; 4) o pouco desenvolvimento das diversas modalidades de esporte e atletismo; esporte entre nós se resume praticamente em futebol (ROSA, 1969a, p. 15).

Desse modo, tendo como justificativa principal a falta de professores formados em Educação Física para atuarem nas escolas de ensino fundamental e médio na cidade de Pelotas e na região, e a recente extensão da obrigatoriedade da Educação Física para todos os acadêmicos pertencentes a qualquer curso superior, em 09/06/1971, sob a portaria n ${ }^{\circ} 12$ I/7 I, o Reitor da Universidade Federal de Pelotas (UFPel) instituiu a criação da Escola Superior de Educação Física da Universidade Federal de Pelotas. Aos 23 de novembro de 1971, uma comissão ficou responsável pela elaboração do primeiro edital do concurso de títulos para provimento por contrato de funções de Auxiliar de Ensino de diversas disciplinas da Escola'!.

Apesar de haver candidatos do sexo masculino e feminino inscritos em todas as disciplinas que havia na seleção; nas disciplinas de Biometria, Socorros de Urgência, Ginástica com peso e halteres, futebol de campo e futebol de salão, foram selecionados somente candidatos homens. Já nas disciplinas de Ginástica Rítmica e Recreação, foram selecionadas mulheres e, para as disciplinas práticas, como o voleibol, o basquetebol, o atletismo e a ginástica, foram selecionados dois professores, um de cada sexo, para trabalhar respectivamente com a turma masculina e feminina. Apesar de não termos feito uma investigação mais detalhada sobre esta seleção, principalmente pela falta de fontes específicas do episódio e dos critérios avaliativos que orientaram a seleção, o resultado é instigante, ele explicita certa segregação por gênero já na constituição do corpo docente.

\section{CORPOS E SEXUALIDADES FEMININAS NO CURRÍCULO SUPERIOR DE EDUCAÇÃO FÍSICA}

Guacira Louro ( 1997b) analisa a história da transformaçã̃o do magistério em uma profissão feminina. Os discursos do século XIX que legitimaram a entrada das mulheres nas escolas estavam intimamente ligados à função da maternidade, ou seja,

[...] se o destino primordial da mulher era a maternidade, bastaria pensar que o magistério representava, de certa forma, a 'extensão da maternidade', cada aluno ou aluna vistos como um filho ou uma filha 'espiritual'" (LOURO, 1997b, p. 450).

1 I. Dados retirados da Ata de instalação do concurso de títulos para provimento de disciplinas da Escola Superior de Educação Física da Universidade Federal de Pelotas. Nessa ata constam os nomes de todos/as os/as professores/as que se inscreveram no concurso e dos/das que, efetivamente, foram aprovados/as. 
Com isso, passam a ser associadas ao magistério características tidas como femininas, tais como paciência, afetividade e vocação. A entrada de mulheres em maioria em um curso de licenciatura em Educação Física pode estar relacionada com a tradição, que instituiu o magistério como um espaço predominantemente feminino ${ }^{12}$.

O lugar reservado a essas mulheres que estão adentrando o espaço institucional da universidade, como alunas ou como professoras, é garantido a partir de toda uma construção padronizada de corpos e de sexualidade, de professor e de professora. Faz-se, assim, toda uma escala e uma classificação dos comportamentos e estratégias de educação corporal pautada por visão binária, que reforça a premissa de que "o corpo humano, lugar de observação constante - lugar dos órgãos, funções elementares, humores - apresenta um traço notável e certamente escandaloso, que é a diferença sexuada e o diferente papel dos sexos" (HÉRITIER-AUGÉ, 1996, p. 19). Esses valores identificados nos discursos e nas práticas curriculares ajudam a instituir no corpo social subjetividades e valores corporais binários, modelos masculinos e modelos femininos.

No arquivo da Escola Superior de Educação Física encontramos a lista de presença da primeira aula prática do currículo, datada de 05/03/1974, ocorrida no Ginásio do Colégio Municipal Pelotense. A lista de presença da disciplina de Ginástica Rítmica reforça a supremacia das mulheres nas primeiras turmas do curso de Educação Física da ESEF/ UFPel, nas quais de um total de 33 alunos/as apenas 9 eram homens. ${ }^{13}$

Um dos fatores para essa supremacia de mulheres pode estar relacionado com a profissionalização do magistério ocorrida nos anos 70, (conforme sinaliza a passagem do depoimento da professora Elisabeth Martins mais a frente). As professoras tornam-se profissionais do ensino em contraposição à figura materna do período anterior:

Esse profissionalismo caracterizava-se pela valorização de um outro tipo de habilidades dos professores e professoras. Agora caía sobre eles uma avalanche de tarefas burocráticas, exigindo-Ihes uma ocupação bastante intensa com atividades de ordem administrativa e

12. Os estudos realizados por Guacira Louro aqui referidos tratam do magistério de $1^{\circ}$ e $2^{\circ}$ graus. Assim, cabe a ressalva de que o Ensino Superior brasileiro nunca foi identificado como um espaço tipicamente feminino, como ocorreu com o magistério de $1^{\circ}$ e $2^{\circ}$ graus. No curso por nós estudado, por exemplo, mesmo no período em que houve uma supremacia de acadêmicas mulheres (primeiras turmas), a maioria do corpo docente era composta por homens.

13. Lista de presença da primeira aula prática, datada de 05/03/I 974. A título de esclarecimento convém destacar que Ginástica Rítmica era uma disciplina obrigatória para homens e mulheres e ofertada em turmas separadas, enquanto Rítmica II e Rítmica III eram disciplinas obrigatórias, mas eram ofertadas somente para as mulheres. 
de controle; determinava-se, também, que sua ação didática se tornasse mais técnica, eficiente e produtiva (LOURO, 1997b, p. 473).

A maioria feminina presente nas primeiras turmas da ESEF/NFPel reflete também uma demanda das escolas da cidade onde:

[...] são muitas as turmas femininas que recebem aulas de Educação Física ministradas por professôres homens; naturalmente que isso não é o ideal, pois os exercícios para o sexo feminino devem ser diferentes dos que são ensinados aos rapazes e nenhum professor gosta de fazer demonstrações de bailado, de balanceio, de dança rítmica (ROSA, 1969a, p. 15.).

Além da falta de mulheres professoras de Educação Física, a citação acima ressalva que "os exercícios para o sexo feminino devem ser diferentes dos que são ensinados aos rapazes". A visibilidade do texto expõe a força dos discursos sexistas na tradição curricular da Educação Física pelotense e brasileira.

Além disso, bailado, balanceio e dança rítmica confrontam com o modelo de masculinidade da época, pois são práticas tidas como femininas. Assim, o autor do artigo do jornal alerta que ministrar aulas para turmas femininas representa um desconforto ao corpo e a masculinidade dos professores (homens) de Educação Física.

Judith Butler (200I) alerta que formamos nossas concepções e representações dos corpos em função de uma representação de mundo que é dual, binária. Essa oposição binária atende a propósitos hierárquicos. Segundo a autora, quando determinamos diferença a partir do sexo, nós restringimos nosso entendimento àquelas partes sexuais que ajudam no processo de reprodução. Assim, é preciso desconfiar desse proceder e perguntar pelas condições de emergência dos sujeitos, pelas contingências sócio-históricas e pelas relações de poder constituintes das diferenças de gêneros.

Nessa época (1969- 1970) Pelotas contava com cerca de cinquenta mil estudantes, incluindo os universitários, que teriam que ser atendidos pela obrigatoriedade da Educação Física curricular; nesse total era grande o número de alunas do sexo feminino, o que, provavelmente, contribuiu para que houvesse uma maior procura para o curso superior de Educação Física, por parte das mulheres.

Mas, além da demanda específica e local, a procura feminina em relação à escolha pelo curso de Licenciatura em Educação Física, também pode estar relacionada a fatores políticos e sociais transversais, como foi o processo da "feminização do magistério", (LOURO, 1997b, p. 449). A entrevistada Elisabeth Martins faz referência a isso, lembrando que: "Eu acho que na época como o magistério era uma profissão essencialmente quase feminina, eram as mulheres que atuavam a título precário na área da educação física, talvez por isso havia um número maior do sexo feminino na primeira turma da ESEF/NFPel" (MARTINS, 2007). 
Em outro artigo publicado no jornal Diário Popular da época, mais uma vez, se faz uma relação entre a Educação Física ministrada no ensino fundamental e médio com o sexo do professor, alegando que:

a criação de uma Escola de Educação Física, em Pelotas, tornará possível a formação de maior número de professoras dessa disciplina, resolvendo o problema da diferenciação do ensino de acordo com o sexo. O referido problema é o responsável pela aversão que muitas jovens têm pelas aulas de Educação Física (ROSA, 1969a, p. I5).

Por lidar diretamente com o corpo, a Educação Física é um palco de visibilidade da sexualidade. As estratégias de ensino, os métodos e os conteúdos específicos das aulas dessa disciplina "permitem que o professor ou professora exercite um olhar escrutinador sobre cada estudante, corrigindo sua conduta, sua postura física, seu corpo, enfim, examinando-o/a constantemente" (LOURO, 1997a, p. 75). Assim, o fato de professores de um sexo terem de ministrar aulas para alunos de outro, mais do que um problema pedagógico, colocava-se como um desconforto moral diante dos valores hegemônicos na sociedade pelotense da época.

A reivindicação (expressa no jornal de maior circulação da cidade) para que homens não ministrassem aulas de Educação Física para mulheres e vice-versa evidencia uma tendência para uma "maximização das diferenças" ${ }^{4}$, mostrando que é justamente quando, "a diferença é pequena, e não quando é acentuada, que o outro se torna alvo de intolerância" (KEHL, 1996, p. 26).

No caso deste estudo específico, é interessante observar como o acesso das mulheres ao curso Superior de Educação da UFPel, em parte, foi justificado por uma intolerância, ou seja, pela impertinência de professores homens ministrarem aulas de Educação Física às mulheres, que haviam adentrado a escola e que começavam a fazer ruído no modelo masculino hegemônico, mas já não havia mais como ignorá-las.

\section{O CURRÍCULO COMO TERRITÓRIO DE RELAÇÕES DE PODER}

$\mathrm{Na}$ análise que realizamos da distribuição das disciplinas da primeira grade curricular da ESEF/UFPel, identificamos que as disciplinas de Rítmica II e Rítmica III (disciplinas da área da dança) eram obrigatórias mas eram ofertadas somente às

14. A psicanalista Maria Rita Kehl (1996, p. 26) comenta que a persistência de valores "essencialistas" tendem a maximizar as 'mínimas diferenças'. Tomando como referência Kehl e seu conceito de 'mínima diferença' apontamos para a necessidade dos discursos da época maximizarem essas diferenças para a garantia da manutenção dos espaços masculinos e femininos. Evitando as ameaças às identidades e aos papeis sociais masculinos e femininos, culturalmente estabelecidos. 
mulheres, enquanto as disciplinas de Futebol I e Futebol II também eram obrigatórias mas somente podiam se matricular alunos do sexo masculino. Parte desta segregação sexual pode ser um reflexo do contexto político cultural predominante na época, expresso, por exemplo, pelo decreto lei no 3199, elaborado em 194I (durante o Estado Novo) e regulamentado em 1965, por uma deliberação do Conselho Nacional de Desporto, que proibia às mulheres a prática de esportes que eram considerados incompatíveis com a sua natureza, como todas as modalidades de lutas, futsal, futebol, pólo aquático, pólo, rúgbi, halterofilismo e beisebol. Este decreto foi revogado somente em 1979 (CASTELANI FILHO, 1998). O currículo prescrevia também que nas disciplinas práticas como o Atletismo, a Natação, a Rítmica I, a Ginástica I e o Voleibol, as turmas fossem sempre separadas por sexo.

Essa pedagogia da separação dos sexos e da "maximização das diferenças" irá se estender para os próximos anos. Os documentos do ano de 1977 mantêm essa separação em função do sexo e estabelecem professores homens para turmas masculinas e mulheres para as femininas. Nas grades de horários semestrais, que era ofertada constava a inscrição: "semestre masculino" e "semestre feminino".

Segundo nossa análise, esse quadro geral se manteve até meados dos anos de 1980. Em 1984, optou-se pela experiência de aulas mistas em todas as disciplinas, inclusive nas consideradas disciplinas práticas. Na ata nº 04 do dia 03/06/I 985, da Reunião de Departamento da Escola Superior de Educação Física, o assunto principal da pauta foi a avaliação do resultado da implementação do trabalho com turmas mistas.

A maioria dos/as professores/as foi favorável à permanência das atividades com turmas mistas e ressaltaram que não encontraram maiores dificuldades nas aulas. No entanto, o professor e a professora da disciplina de Atletismo afirmaram preferirem turmas separadas por sexo. Segundo registro no documento, tais professores afirmavam que a separação facilitava a aprendizagem dos alunos. $\bigcirc$ professor da disciplina de Handebol comentou que nas aulas práticas as turmas deveriam ser separadas porque com turmas mistas os rapazes eram prejudicados em termos de rendimento.

A reunião foi encerrada propondo encaminhamentos, tais como:

I) descobrir a opinião dos alunos a respeito do assunto, para que isso pudesse ser levado em conta;

2) comparar as avaliações práticas das turmas separadas e mistas, para analisar quais tinham melhor rendimento;

3) construir os horários de modo que fosse possível separar as turmas que pudessem ter problemas. Nas atas das reuniões subseqüentes não foram encontradas novos registros sobre este assunto. Todavia, através das grades de horários dos semestres posteriores, verificou-se que houve uma manutenção da experiência com as turmas mistas. 
Esta mudança curricular, instituída na ESEF/UFPel a partir de 1984, criando turmas mistas em todas as disciplinas, pode ser considerada um marco, um momento de ruptura curricular na Educação Física brasileira, principalmente por que em outros cursos superiores, nesta mesma data, continuava havendo a separação por sexo. Em algumas, como é o caso da Universidade Federal de Santa Maria, por exemplo, neste mesmo ano (1984), além das aulas práticas serem separadas, o próprio ingresso no curso era divido: 25 vagas para homens e 25 vagas para mulheres.

A professora Elisabeth Martins contou um pouco sobre como ocorreu esse processo na ESEF/UFPel, lembrando que:

Seria até folclórico contar essas coisas, mas é para ver como as cabeças funcionavam na época, em relação ao corpo. As nossas aulas eram separadas por sexo, ainda dentro daquela idéia de que o rapaz tem mais força para realizar algumas atividades, outras seriam mais femininas, como a dança, a ginástica rítmica; então todas as nossas aulas eram separadas. Quando eu ingressei, a trabalhar com a área da ginástica na ESEF, ainda eram assim, mas por pouco tempo, nos estávamos num re-estudo de currículo onde se concluía que isso não era o mais importante e daí, então, as turmas passaram a ser mistas (MARTINS, 2007).

\section{CONSIDERAÇÕES FINAIS: ESCOLA DE FORMAÇÃO FEMININA}

O que buscamos ao longo dessa pesquisa foi explicitar como as diferentes instituições - nesse caso uma instituição acadêmica de formação de professores/as de Educação Física - e as distintas práticas curriculares são constituídas e também são constituintes das relações sociais de gênero, ressaltando a dimensão política e cultural que atravessa os Estudos de Gênero. A universidade, assim como as escolas com suas práticas curriculares, tornam os espaços de formação generificados.

Mais do que algumas histórias de mulheres e sobre as mulheres, o estudo procurou analisar como se deu a construção cultural e social do masculino e do feminino, considerando como os sujeitos se constituem em meio às práticas curriculares e às relações poder. Assim, através de uma gênese da emergência e consolidação da Escola Superior de Educação Física da Universidade Federal de Pelotas, foi possível evidenciar que as práticas curriculares e o processo de formação de professores/ as de Educação Física esteve sintonizado com os discursos sociais da época, que conclamavam por uma "maximização das diferenças" perante homens e mulheres. Esses discursos adentram o campo educacional repercutindo na relação professor/a - alunos/as nas práticas da Educação Física, tanto no ensino fundamental e médio quanto nos cursos superiores.

Os conteúdos, as metodologias, os regimentos e regulamentos, ou seja o currículo dos cursos Superiores de Educação Física, trazem em sua gênese essa 
história, que implícita e explicitamente reforçou as diferenças sociais, corporais e sexuais entre meninos e meninas; universitários e universitárias; professores e professoras; masculino e feminino.

Como identificamos em nossa pesquisa, tal concepção provem desde as justificativas que conclamam pela criação da ESEF/UFPel, e adentram a estrutura física e curricular dessa instituição e se proliferaram nas escolas e nas aulas de Educação Física, tornando-se uma adversidade para a diversidade nas construções de gênero. Atrelada em bases biológicas conservadoras, a Educação Física foi cooptada para ajudar a reforçar a "maximização das diferenças" entre homens e mulheres.

Cabe salientar que as histórias aqui narradas em nenhum momento pretenderam representar uma versão homogênea e linear dos acontecimentos. Tensões, reivindicações, macros e micros resistências, fizeram parte dessas histórias. Como lembra Margaret Rago, apesar de ter sido um período de ditadura, os anos 60 e 70 também foram um tempo de conquistas dos movimentos feministas. Segundo esta autora, no Brasil e em outros países, é somente nessa época que "entra em cena o clitóris, no contexto de toda uma discussão que redefiniu o lugar social e sobretudo sexual da mulher" (RAGO, 2002, p. 193).

No plano específico do currículo da ESEF/UFPel, alguns sinais desses tempos (feministas) estão presentes no fim das turmas separadas por sexo, não mais existência de disciplinas exclusivas para homens ou para mulheres e também nas outras mudanças curriculares que essas ajudaram a produzir. Assim, atualmente, com a implementação das turmas mistas nos currículos superiores e com as inúmeras iniciativas pedagógicas que se pautam pela coeducação no ensino fundamental e médio, é possível afirmar que as práticas e os discursos quanto ao gênero no campo da Educação Física não são os mesmos de outrora, apesar dos resquícios que provavelmente persistem ${ }^{15}$.

School training of teachers: the gender relations in the curriculum higher of Physical Education

ABSTRACT: The gender relations continue to be a recurring theme in the field of Physical Education. In that sense, this paper aims to investigate how gender relations were present in the emergence and consolidation of the curriculum of the School of Physical Education, Federal University of Pelotas (ESEF/UFPel). The methodology for conducting the research was to Oral

15. Uma análise pontual sobre como os professores de Educação Física do ensino fundamental e médio vêm lidando com o dilema de separar ou não os meninos das meninas em suas aulas e as possíveis conseqüências advindas de uma ou de outra decisão, consultar: Louzada, Votre e Devide (2007). 
History. Thus, by collecting five (5) oral testimony, written historical sources (newspapers, records and documents separate) and the theoretical support post structuralist, we conclude that the emergence of ESEF/UFPel and their curriculum practices in 1970 and 1980 were linked to discourses and practices that reiterated the maximization of differences between the sexes, men and women.

KEYWORDS: Curriculum; gender relations; institutional memory; teacher training.

\section{Escuela de formación para profesores: relaciones de género en el currículo superior de Educación Física}

RESUMEN: Las relaciones de género siguen siendo un tema recurrente en el ámbito de la Educación Física. Por lo tanto, este artículo tiene como objetivo investigar cómo las relaciones de género están presentes en el surgimiento y la consolidación del plan de estudios de la Escuela de Educación Física de la Universidad Federal de Pelotas (ESEF/UFPEL). La metodología para llevar a cabo la investigación fue la historia oral. Así, mediante la recopilación de cinco (5) testimonio oral, fuentes históricas escritas (diarios, registros y documentos separados) y la base teórica proveniente de lo post-estructuralismo, se concluye que la aparición de ESEF/UFPEL y sus prácticas curriculares en 1970 y 1980 estaban vinculados a los discursos y prácticas que reiteró la maximización de las diferencias entre los sexos, los hombres y mujeres.

PALABRAS CLAVE: Plan de estúdios; relaciones de género; memória institucional; formación del profesorado.

\section{REFERÊNCIAS}

AMADO, J.; FERREIRA, M. (Org.). Usos \& abusos da história oral. Rio de Janeiro: Fundação Getulio Vargas, 1998.

BRASIL. Decreto-Lei n 705, de 25 de julho de 1969. Altera a redação do art. 22 da Lei n. 4.024, de 20 de dezembro de 196 I. Coleção de Leis do Brasil, São Paulo, v. 5, p. 47, 1969.

Lei $n^{\circ}$ 4.024, de 20 de dezembro de 1961. Fixa as diretrizes e bases da educação nacional. Diário Oficial da União, Brasília, DF, 27 dez. 1961. Seção I, p. I I.429. Poder Executivo.

Decreto $n^{\circ}$ 69.450, de $1^{\circ}$ de novembro de 1971. Regulamenta o artigo 22 da Lei n. 4.024, de 20 de dezembro de 196I, e alínea c do artigo 40 da Lei n. 5.540, de 28 de novembro de 1968 e dá outras providências. Diário Oficial da União, Brasília, DF, seção I, p. 8826.

BUTLER, J. Fundamentos contingentes: o feminismo e a questão do pós-modernismo. Cadernos Pagu, Campinas, n. I I, p. I I-42, 1998.

Problemas de gênero: feminismo e subversão da identidade. Rio de Janeiro:

Civilização Brasileira, 2003. 
Corpos que pesam: sobre os limites discursivos do sexo. In: LOURO, G.

(Org.). O corpo educado: pedagogias da sexualidade. Belo Horizonte: Autêntica, 200 I. p. $151-172$.

CASTELLANI FILHO, L. Educação física no Brasil: a história que não se conta. Campinas: Papirus, 1988.

ESCOLA SUPERIOR DE EDUCAÇÃO FÍSICA. Ata de instalação do concurso de títulos da Escola Superior de Educação Física da Universidade Federal de Pelotas. Pelotas, 23 nov. I 97I.

Ata da Reunião de Departamento da Escola Superior de Educação Física.

Pelotas, 03 jun. 1985.

. Caderno de orientação aos alunos e alunas. Pelotas, 1980.

Portaria n ${ }^{\circ} 12$ I/7I, de 09/06/1971 - Criação da Escola Superior de Educação

Física da Universidade Federal de Pelotas. Pelotas, 1971.

Lista de eleição dos representantes discentes junto aos Colegiados da UFPEL.

Pelotas, 04 out. 1977.

ESTEVES, W. M. Entrevista concedida a V.T.S. Pelotas, 29 set. 2007.

FERREIRA, M. (Org.). História oral: desafios para o século XXI. Rio de Janeiro: Fiocruz, 2000.

FOUCAULT, M. História da sexualidade 1: a vontade de saber. Rio de Janeiro: Graal, 1977.

História da sexualidade 2: o uso dos prazeres. Rio de Janeiro: Graal, 1984a.

História da sexualidade 3: o cuidado de si: Rio de Janeiro: Graal, 1984b.

Vigiar e punir: história da violência nas prisões. Petrópolis: Vozes, 1987.

Microfísica do poder. Rio de Janeiro: Graal, 1979.

GOELLNER, S. et al. ESEF 65 anos: entre memórias e histórias. Movimento, Porto Alegre, v. II, n. 3, p. 201-2I8, set./dez. 2005.

HÉRITIER-AUGÉ, F. Masculino feminino: o pensamento da diferença. Lisboa: Instituto Piaget, 1996.

JÓDAR, F.; GÓMEZ L. Experimentar o presente: sobre a conformação de novas identidades. Educação \& Realidade: dossiê Michel Foucault, Porto Alegre, v. 29, n. I, p. I39- I53, jan./ jun. 2004.

KEHL, M. R. A mínima diferença: masculino e feminino na cultura. Rio de Janeiro: Imago, 1996. 
LOURO, G. Gênero, sexualidade e educação: uma perspectiva pós-estruturalista. Petrópolis: Vozes, 1997a.

Mulheres na sala de aula. In: DEL PRIORE, M. (Org.). História das mulheres no Brasil. São Paulo: Contexto, 1997b. p. 443-48I.

(Org.). O corpo educado: pedagogias da sexualidade. Belo Horizonte:

Autêntica, 2001.

LOUZADA, M.; VOTRE, S.; DEVIDE, F. Representações de docentes acerca da distribuição dos alunos por sexo nas aulas de Educação Física. Revista Brasileira de Ciências do Esporte, Campinas, v. 28, n. 2, p. 55-68, jan. 2007.

MARTINS, E. F. Entrevista concedida a V.T.S. Pelotas, 29 out. 2007.

MAZO, J. A História do Centro de Educação Física e Desportos da Universidade Federal de Santa Maria. Santa Maria: Ed. da UFSM, 1997.

Memórias da Escola Superior de Educação Física da Universidade Federal do Rio Grande do Sul (ESEF/UFRGS): um estudo do período de sua fundação até a federalização (1940 - 1969). Movimento, Porto Alegre, v. II, n. I, p. I43- I67, jan./abr. 2005.

MEIJER, I.; PRINS, B. Como os corpos se tornam matéria: uma entrevista com Judith Butler. Revista Estudos Feministas, Florianópolis, v. 10, n. I, p. I 55- 167, jan. 2002.

MONTENeGrO, A. T. História, metodologia, memória. São Paulo: Contexto, 2010. ; Invenção do olhar. In: SIMSON, O. R. M. (Org.). Os desafios contemporâneos da história oral. Campinas: UNICAMP/CMU, 1997. p. 197-211.

PORTELLI, A. Ensaios de história oral. São Paulo: Letra e Vozes, 2010.

RAGO, M. Os mistérios do corpo feminino, ou as muitas descobertas do clitóris. Projeto História: revista do programa de Estudos Pós-Graduados em História do Departamento de História da Pontifícia Universidade Católica de São Paulo, São Paulo, v. 21 , n. 25, p. I 8 I 194, dez. 2002.

ROSA, M. Conselho Municipal de Desportos pediu criação de escola de Educação Física na UFPEL. Jornal Diário Popular, Pelotas, 24 ago. 1969a. p. I0- 15.

Educação física para 12.000 alunos, apenas 24 professores. Jornal Diário Popular, Pelotas, 04 out. 1969b. p. 5.

SILVA, T. T. Documentos de identidade: uma introdução às teorias do currículo. Belo Horizonte: Autêntica, 1999.

Teoria cultural e educação: um vocabulário crítico. Belo Horizonte: Autêntica, 2000. 
O currículo como fetiche: a poética e a política do texto curricular. Belo Horizonte: Autêntica, 2003.

SOARES, C. L. Educação física: raízes européias e Brasil. Campinas: Autores Associados, 1994.

THOMPSON, P. A voz do passado: história oral. Rio de Janeiro: Paz e Terra, 1992.

Recebido: 10 ago. 2010 Aprovado: 05 maio 201 I

Endereço para correspondência:

Viviane Teixeira Silveira

Rua Lajeado, n०I05

Bairro Laranjal

Pelotas-RS

CEP: $96090-380$ 